\title{
Optimal Harvesting of a Prey-Predator Fishery: An Overlapping Generations Analysis*
}

\author{
Burcu Özgün** \\ Middle East Technical University
}

\author{
Özgen Öztürk ${ }^{* * * *}$ \\ Middle East Technical University
}

\author{
Serkan Küçükșenel***** \\ Middle East Technical University
}

\begin{abstract}
Maximum sustainable yield (MSY) and maximum economic yield (MEY) harvesting strategies are characterized using an overlapping generations (OLG) model of heterogeneous (prey predator) fishery. A proper modeling of real-life cycle dynamics of fish is introduced with a commonly used prey-predator interaction system of equations to create heterogeneity. Preypredator interaction is modeled with three different functional forms: prey dependent, predator dependent and ratio dependent. MSY and MEY harvesting strategies with these three different forms are given under perfect and imperfect fishing selectivity and presented both numerically and graphically.
\end{abstract}

Keywords: Bioeconomics, Maximum Sustainable Yield, Maximum Economic Yield, Overlapping Generations, Prey-Predator Fishery.

JEL Classification: D04, D78, Q22.

\section{Av-Avcı Balıkçılığında Optimal Avlanma: Ardışık Nesiller Analizi}

\section{Özet}

Maksimum sürdürülebilir mahsul (MSM) ve maksimum ekonomik mahsul (MEM) avlanma stratejileri heterojen (av-avcı) ardışık nesiller balık popülasyon modeli içerisinde tanımlanmıştır. Balık popülasyon dinamikleri gerçekçi bir model ile ele alınmış ve yazında yaygın olarak kullanılan av-avcı etkileşim denklemleri modelimize entegre edilmiştir. Üç farklı formdaki av-avcı etkileşim denklemleri (av bağımlı, avcı bağımlı ve orana bağlı) ile tam veya kısıtlı ağ seçiciliği teknoloji koşulları altında maksimum sürdürülebilir mahsul ve maksimum ekonomik mahsul avlanma stratejileri numerik olarak çözülmüş ve sonuçlar grafiksel olarak sunulmuştur.

Anahtar Kelimeler: Biyoekonomi, maksimum sürdürülebilir mahsul, maksimum ekonomik mahsul, ardışık nesiller modeli, av-avcı popülasyon modeli.

JEL Sinıflandırmasi: D04, D78, Q22.

\footnotetext{
* This research was supported by the Turkish Scientific and Technical Research Council (TÜBİTAK) Grant No. 3501-114K957. All errors are ours

** Middle East Technical University, Department of Economics. E-mail: bozgun@metu.edu.tr.

**** Middle East Technical University, Department of Economics. E-mail: ozgen.ozturk@metu.edu.tr

**** Corresponding Author. Middle East Technical University, Department of Economics. Email: kuserkan@metu.edu.tr.
} 


\section{Introduction}

Guaranteeing the long-term sustainability of fisheries in both biological and economic terms is very important, and the determination of optimal harvesting strategies, accordingly, has been a focal issue in the design of fishery management systems. To achieve sustainable development of fisheries, the implementation of maximum sustainable yield (MSY) and maximum economic yield (MEY) harvesting strategies have generally been suggested as one of the main targets for institutions that are responsible for regulating and supervising fishery sectors. While there are studies modeling fish population dynamics and investigating optimal harvesting strategies under a single type of fish population (see, among others, Skonhoft et al., 2012; Skonhoft and Gong, 2014; Kanık and Küçükşenel, 2017), heterogeneous fish models have not yet been well studied within this context. Since the exploitation of fishery resources is not the sole factor affecting fish population dynamics, biological constraints and interactions in the ecosystem should also be considered in the determination process of optimal harvesting strategies. The characterization of optimal harvesting strategies under different biological prey-predator fish population models, to the best of our knowledge, is still an open question. We aim to at least theoretically fill this gap in this paper by characterizing optimal harvesting strategies for different heterogeneous type prey-predator models. This may shed light on how policy makers can implement the optimal harvesting strategies for real-life fisheries.

In heterogeneous type modeling strategies, dynamics of interaction between prey and predator fish are captured by the trophic function.5 There are three widely accepted approaches to the trophic function's arguments in the literature: prey-dependent, predator dependent and ratiodependent. Abrams and Ginzburg (2000) suggest that the appropriate function is Holling Type2 (Holling, 1959), arguing that the predator population is actually a function of the prey population. According to Holling (1959), the trophic function should only depend on the prey population. Beddington (1975), on the other hand, claims the opposite and indicates that the prey population is a function of the predator population. Combining the two approaches, Arditi and Ginzburg (1989) argue that the function should depend on neither type alone, but instead should have a proportional structure (ratio of prey to predator population). In this study, all of these three different approaches, Holling (1959), Beddington (1975), and Arditi and Ginzburg (1989) are employed to explain the dynamics between species. The dynamics of both prey and predator populations have then been analyzed under Maximum Sustainable Yield (MSY) and Maximum Economic Yield (MEY) harvesting strategies.

Instead of previously used age-structured homogenous fish population models, an overlapping generations model is employed and both prey and predator populations are modeled in a generational accounting setting which models both species as having four different periods in their life-cycle. We focus on the issue of the reaction of the populations to their intrinsic interaction mechanisms and propose optimal harvesting strategies for all different interaction modeling techniques. Optimal harvest rates for MSY are found using the grid-search algorithm method, which differs from the methods used in the literature related to finding MSY harvesting strategies. Our results suggest that although the overlapping generations model provides a more accurate approach, the results are coherent with the age-structured model. In both models, all generations of old mature fish (regardless of prey or predator species) are

\footnotetext{
${ }^{1}$ Throughout the study, trophic function and interaction function terms are used interchangeably.
} 
harvested under MSY harvesting strategies, and we observe age-selective harvesting. For reallife fisheries, it may not be possible to harvest all old mature fish due to the need for excessive fishing efforts. However, our model suggests that primarily old-mature fish have to be targeted to achieve MSY for real-life fisheries.

The MEY problem is analyzed under both perfect fishing selectivity and imperfect fishing selectivity cases. Perfect fishing selectivity implies that each fleet harvests the targeted species and age but does not harvest other fish species and ages. However, imperfect fishing selectivity implies that a fleet harvests targeted fish species and ages but also may mistakenly harvest other species and ages. By using simulations, we determine the optimal harvesting levels (for each type and age group) required to maximize the total biomass and economic profits in an infinite time horizon under biological and economic constraints. In this paper, we only provide a characterization of MEY harvesting strategies. The implementation of these strategies for real-life fisheries is left for future research. Outcomes of this study can be used to design a new quota management or allocation system for fisheries with prey and predator fish population dynamics.

The rest of the paper is organized as follows. In Section 2, the interaction of heterogeneous fish populations within the overlapping generations model is introduced. In Section 3, MSY formulation is explained in detail, the solution methodology of the model is described, and the results along with the calibration parameters are presented. In Section 4, the MEY problem is solved under the perfect and imperfect fishing selectivity cases with corresponding harvest rates and effort levels. Section 5 puts important aspects together to discuss possible road maps for future studies and conclusions.

\section{OLG Fish Population Model}

In order to analyze optimal harvesting strategies, life cycle behaviors of each fish population must be well demonstrated. Each population has its own dynamics and the modeling has to be done in accordance with these dynamics. In this paper, contrary to previous papers using agestructured models with single fish population (Reed, 1980; Botsford, 1981; Gurtin and Murphy, 1981; Getz and Haight, 1989), we use the overlapping generations model to capture the life-cycle dynamics of the prey and predator fish population. The overlapping generations model can be considered as a subset of age-structured models in which there are simultaneously living fish from all ages at a given period of time $t .{ }^{6}$ Accordingly, through a recruitment process, each period new juveniles enter the ecosystem and some of the incumbents leave the ecosystem by dying. Each cohort in the ecosystem can be represented by the following $m \times n$ matrix.

\footnotetext{
${ }^{2}$ Each period in the life-cycle of fish are referred to as age throughout the paper although a period does not necessarily correspond to one year.
} 


$$
\left[\begin{array}{llll}
\vdots & \vdots & \vdots & \vdots \\
X_{s, t} & X_{s+1, t} & X_{s+2, t} & X_{s+3, t} \\
X_{s, t+1} & X_{s+1, t+1} & X_{s+2, t+1} & X_{s+3, t+1} \\
X_{s, t+2} & X_{s+1, t+2} & X_{s+2, t+2} & X_{s+3, t+2} \\
X_{s, t+3} & X_{s+1, t+3} & X_{s+2, t+3} & X_{s+3, t+3} \\
X_{s, t+4} & X_{s+1, t+4} & X_{s+2, t+4} & X_{s+3, t+4} \\
\vdots & \vdots & \vdots & \vdots
\end{array}\right]
$$

Figure 1: Time and Generation Dimension in the Ecosystem

Each element of the matrix carries generation and time information; $t$ indicates time, $s$ indicates age. For example, the first element, $X_{s, t}$, represents the total number of $X$ type fish at the age of $s$ at time $t$.

In our setting, there are four different age-classes, i.e. in each period t, fish of ages 0, 1, 2 and 3 are present in the ecosystem. Fish enter the system at age- 0 as juveniles, after the recruitment process, and leave it at the end of age 3 from natural causes. Juveniles are the fish that have not reached their adult forms yet and are assumed to have no economic value due to their size and weight. Age 1 and 2 fish are defined as the young and old matures respectively, and they are involved in the spawning process. Age 3 is the last period of the lifecycle of fish before their natural death. Spawning is assumed to occur before the prey-predator interaction occurs and just before the exploitation period.

In order to incorporate heterogeneity in fish population, we introduce prey and predator species that are constantly interacting with each other. The number of fish in each type is denoted by $X_{i, t}$ where $i$ and $t$ correspond to age and period respectively. As stated before, there are two types of fish; prey $(N)$ and predators $(P)$. However, analyzing an ecosystem with prey and predator species constantly interacting each other is not an easy task. One has to consider the dynamic aging process of each type along with the interaction between the species. Thus, the algorithm has two layers: in the inner loop each population grows in accordance with its internal dynamics; in the outer loop, interaction is calculated and the population of each species is determined accordingly. Therefore, we denote the population at age $i$ and period $t$ as

$$
X_{i, t}=\left\{N_{i, t}, P_{i, t}\right\} \text { and } i \in\{0,1,2,3\} \text {. }
$$

The total number of prey and predator at any period $t$ are the sum of the population of the corresponding type of each age as stated in Equation 2.

$$
X_{t}=\sum_{i=0}^{3} X_{i, t} \quad \text { for all } t .
$$

Each period, young mature (age 1) and old mature (age 2) join the recruitment process and spawn the juveniles of the preceding year of its own type. The recruitment process is governed by the function given in equation 3 and the same applies for both types. 


$$
X_{0, t+1}=\operatorname{Rec}(t+1)=\frac{a\left(X_{1, t}+\beta X_{2, t}\right)}{b+X_{1, t}+\beta X_{2, t}}
$$

Juveniles, those who survived natural death and prey-predator interaction at the end of one period, become young matures, as stated in equation 4. Young and old mature fish of each type on the other hand are faced with another exploitation type which is the human activity of fishing denoted by $h$, given in equations 5 and 6 :

$$
\begin{aligned}
& X_{1, t}=X_{0, t-1}^{\prime} s_{0} \\
& X_{2, t}=X_{1, t-1}^{\prime} s_{1}\left(1-h_{1 X, t-1}\right) \\
& X_{3, t}=X_{2, t-1}^{\prime} s_{2}\left(1-h_{2 X, t-1}\right)
\end{aligned}
$$

Figure 2 provides a summary of events in the life span of a fish generation for both prey and predators. Figure 2 can be helpful to visualize the life-cycle of a cohort in a timeline form.

Figure 2: Life-Span of a Cohort

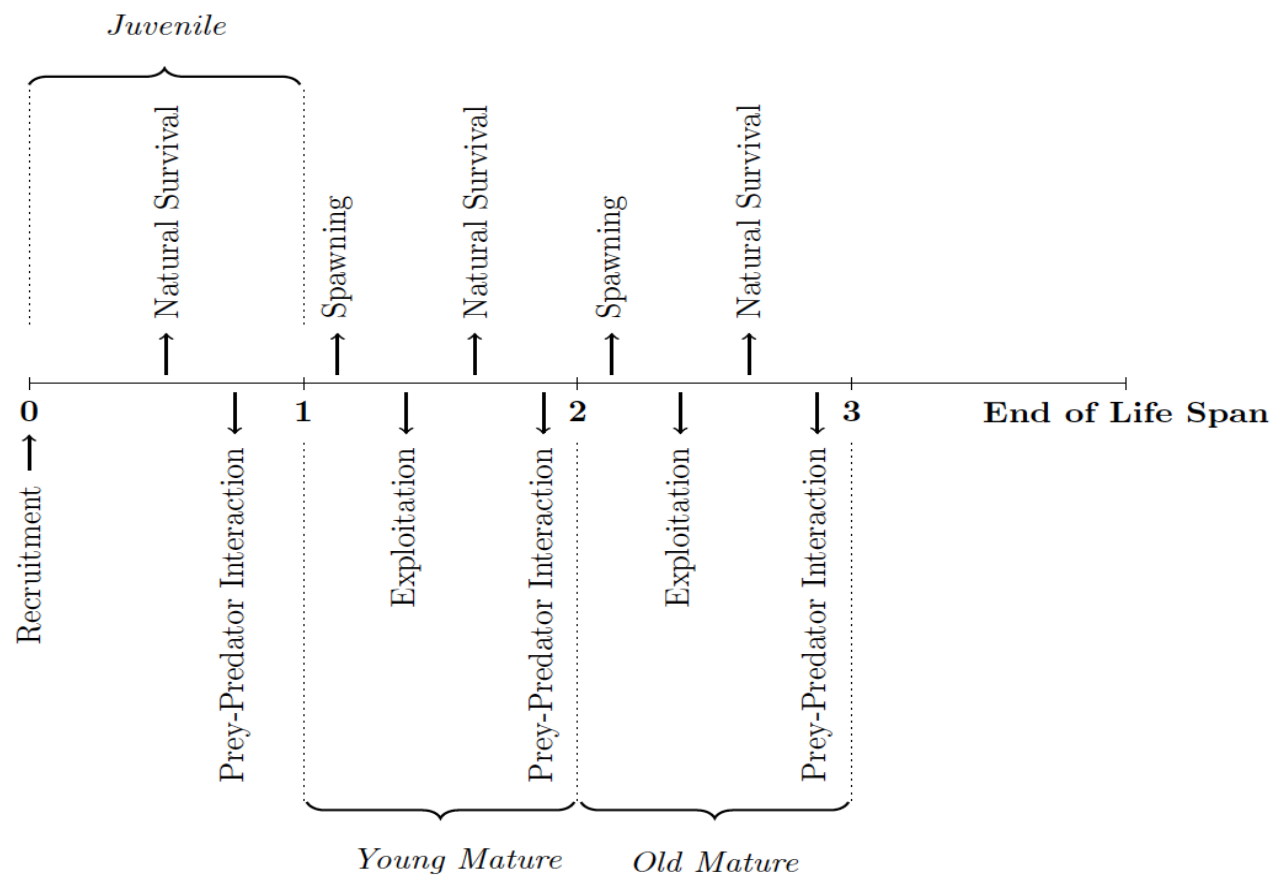

To model prey-predator interaction, we use the discrete version of differential models which are frequently used in the literature. In the equation system which consists of Equations 7 and 8, function $g$ is named differently as functional and numerical response (Akcakaya et al. (1995)). Also, $e$ denotes trophic efficiency.

$$
\begin{array}{r}
N_{t}^{\prime}=N_{t}-\mathbf{g}\left(N_{t}, P_{t}\right) P_{t} \\
P^{\prime}{ }_{t}=\operatorname{eg}\left(N_{t}, P_{t}\right) P_{t}
\end{array}
$$


The equation system governs the growth rates of both species. These growth rates have been distributed to the population of different generations by the age-dependent $m_{X i}$ parameter. As experience increases, the chance of being advantageous in the prey-predator interaction increases, so the model is calibrated in a way that $m_{X i}$ increases with the age of the fish. There are three commonly used formulations in the literature for the response function, $g$ : Beddigton and De-Angelis et al. (1975) (predator-dependent), Arditi and Ginzburg (1989) (ratio-dependent), and Okuyama and Ruyle (2011) Holling Type II (prey-dependent). This study uses all three functional responses, given in the following equations 9, 10 and 11.

$$
\begin{array}{rlrl}
\boldsymbol{g}\left(N_{t}, P_{t}\right)=\frac{s N}{1+v P+s w N} & & \text { (Beddington and DeAngelis) } \\
\boldsymbol{g}\left(N_{t}, P_{t}\right)=\frac{s N / P}{1+s w N / P} & & \text { (Arditi and Ginzburg) } \\
\boldsymbol{g}\left(N_{t}, P_{t}\right)=\frac{s N}{1+s w N} & \text { (Holling Type II) }
\end{array}
$$

The modeling approach employed in this section provides a well-suited population dynamics system to investigate the effects of interactions between the types and exploitation of different types and age groups while also allowing for dynamics with demonstration of transition paths.

\section{Maximum Sustainable Yield}

In this section, the problem of maximizing the harvest rate is discussed in detail, provided that the sustainability of fish populations is preserved. In this environment, the optimization problem is the maximization of total harvest, equation 12 , in an infinite time horizon under the biological constraints defined by equations $3,4,5$ and 6 .

$$
\max \sum_{y} Y_{t}
$$

In equation $12, Y_{t}$ refers to total harvested biomass at time $t$. Total harvested biomass is the total amount of harvested fish from all economically valuable ages.

$$
Y t=h N_{1} N_{1}, t w N_{1}+h N_{2} N_{2}, t w N_{2}+h P_{1} P_{1}, t w P_{1}+h P_{2} P_{2}, t w P_{2}
$$

In equation (13), $w_{N 1}$ corresponds to the weight of prey young mature, while $h_{N 1}$ is the harvesting level of prey young mature. While $h_{P 2}$ represents the harvesting rate of the old mature fish in the predator species. Other species and age groups are similarly defined.

The values of the parameters and definitions are presented in details in Table 1. All Tables are delegated to Appendix. All of the scaling, fertility and shape parameters, survival rates and weights are taken from Skonhoft et al. (2012). Although the current choice of parameters corresponds to the variables related to salmon life-cycle, our sensitivity analysis shows that the results are robust to parameter choice and the main findings of this study, without loss of generality, can be extended to other fish populations. ${ }^{7}$ In the MSY problem, choice variables are the harvest rates, $h_{N 1}, h_{N 2}, h_{P 1}, h_{P 2}$. The grid search method is used to find the optimal harvest rates. With this method, harvesting rates that optimize total sustainable yield under the

\footnotetext{
${ }^{3}$ The sensitivity analyses are available upon request.
} 
necessary biological constraints are sought in a 4-dimensional matrix $[0.01,0.99]^{4}$. That is, for each possible $h_{X t}$, total harvested biomass is recorded and the algorithm chooses the quartet of harvest rates corresponding to the entry with maximum value of the Total Harvested Biomass matrix as a solution.

As expected, the algorithm chooses the rate which forces to harvest an entire generation of old mature fish (regardless of prey or predator species). That is, the solution is the highest allowed value of 0.99 for the harvest rate $\left(h_{N 2}=0.99\right.$ and $\left.h_{P 2}=0.99\right)$. Furthermore, a corner solution for old mature fish always maximizes the total biomass harvested, since the exploitation happens after spawning. If some old mature fish survive both types of mortality they will become age 3 in the next period, and die. Thus, predicting that old mature fish will not have any economic value unless they are harvested, the algorithm offers the optimal solution for the fleet as the highest possible value for $h_{2}$. The optimal catch rates for young mature fish are 0.01 for prey species and 0.99 for predator species $\left(h_{N_{1}}=0.01\right.$ and $\left.h_{P_{1}}=0.99\right)$. The reason for the algorithm's desire to harvest the entire predator population stems from the fact of the predators' negative effect on the total biomass. In addition, the reason for the algorithm's unwillingness to harvest the prey species is that the young mature prey participates in the spawning one period later, also becoming even heavier and more economically valuable.

Figure 3 reveals the total biomass over time under the MSY harvesting strategy for three different trophic functions.

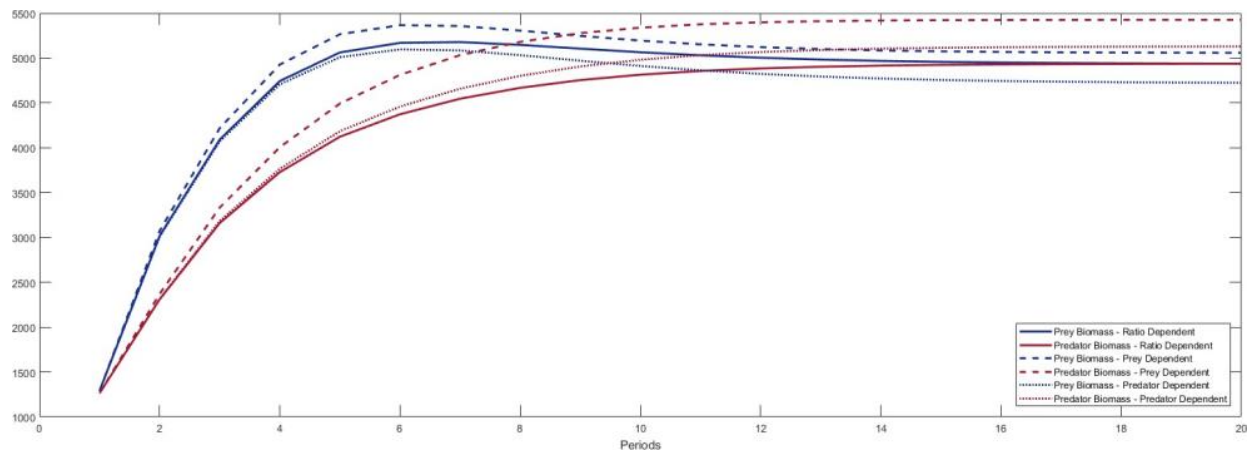

Figure 3: Biomass over Time under MSY Harvest Strategy

As presented in Figure 3, both prey and predator populations increase and reach a steady state level. Our finding is that the choice of different trophic functions gives similar results and hence, in terms of biomass, the form of trophic function does not matter for implementing MSY.

Although the findings are consistent with the literature (Ahrens et. al., 2020), harvesting all old fish or all predators for real life fisheries requires an infinite fishing effort and hence may not be implementable as an outcome of a management system. Therefore, it may not be possible to harvest all old mature fish for real-life fisheries. However, our model suggests that primarily old mature fish have to be targeted to achieve MSY for real-life fisheries. We want to point out that there is still an ongoing debate in the literature on whether old fish should be targeted or not. Some researchers argue that fishing extensively old mature fish populations decreases the old mature fish population disproportionately, and this type of 
exploitation eventually harms the dynamics of the population due to unbalanced age structure and evolutionary reasons (Barnett et al, 2017; Garcia et al. 2012; Law and Plank, 2018; Birkeland and Dayton, 2005). However, there are also studies arguing that young fish should be spared and old fish should be targeted to implement optimal harvesting strategies (Diekart et.al., 2010; Kanık and Küçükşenel 2016). In this line of research, Froese et. al., (2016) show that empirical evidence does not support balanced fishing arguments which is against age-specific harvesting. They also claim that this approach of balanced fishing cannot be used for sustainable fisheries. Our study provides a theoretical contribution to this debate by showing that age-specific harvesting, requiring a corner solution where all old mature fish are harvested, also maximizes the sustainable biomass for prey-predator fisheries.

\section{Maximum Economic Yield}

In this section we now begin to analyze the maximum economic yield harvesting strategy. There are four different fleets which target young and old mature groups of prey and predator fish. Under the perfect fishing selectivity case, each fleet only harvests the targeted species and age group while under the imperfect fishing selectivity case, in addition to targeted fish, by-catch harvest happens for all untargeted age groups and species. Model parameters are again calibrated using the values given in Table 1 and additional parameters required for MEY analysis are given in Table 2 .

In this problem, a social planner is assumed to maximize the total economic yield for current and all future periods for all four fleets of the representative fishing agent. That is, the problem of the social planner is to maximize the sum of profits of the fishery sector.

$$
\max \sum_{t} \Pi_{t}
$$

Profit for a given period t i.e.; $\Pi_{t}$ is calculated by subtracting the costs from the sum of monetary value of the harvest in the corresponding period given in equation 15 .

$$
\max \sum_{t} \sum_{i} p_{i X, t} h_{i X, t}-C_{i X, t}
$$

In equation 15, $p_{i X, t}$ stands for the price of $i$-aged fish $X$ at time $t$, whereas $h_{i X, t}$ and $C_{i X, t}$ stand for harvest rate and cost of harvesting respectively for the same subset of fish population. Harvest rate on the other hand is a function of effort exerted for the specific type and age fish and is calculated based on the seminal work of Grafton et al. (2010) given in equation 16.

$$
h_{i X, t}=q_{i X}\left(b_{i X, t}\right)^{\mu} E_{i X, t}^{\eta}
$$

In equation $16, \mu$ is the sensitivity of the amount of harvest to the size of the corresponding fish population, i.e., stock effect $\eta$ is the marginal product of fishing effort, $q_{i x}$ is the coefficient of catchability and lastly $b_{i X, t}$ is the biomass index defined in $[0,1]$ given as

$$
b_{i X, t}=\frac{x_{i, t}^{\prime} w_{i X}}{\sum_{i} X_{i, t}^{\prime} w_{i X}} \text { for all } i \in\{0,1,2,3\}
$$


Fishing cost on the other hand is represented by $C_{i X}$ and is a linear function of fishing effort given in equation 18 where $c_{i X}$ is the constant marginal cost of per unit effort.

$$
C_{i X}=c_{i X} E_{i X, t}
$$

Under the imperfect fishing selectivity case, $i X \in\{N 1, N 2, P 1, P 2\}$ fleet harvests not only targeted $i$-aged $\mathrm{X}$ fish, but also harvests $j$-aged $Y$ fish by-catch. This situation is integrated to the model with equation 19 and unintended catchability coefficients $\tilde{q}_{i X}$ are defined as in Skonhoft et al. (2012). Also, $\tilde{h}_{i X, t}$ denotes the unintended harvest rates at any given time $t$.

$$
\begin{gathered}
\tilde{h}_{i X, t}=\sum_{j, Y} \tilde{q}_{j Y, i X}\left(b_{i X, t}\right)^{\mu} E_{j Y, t}^{\eta} \\
Y^{\prime}{ }_{i, t}=\left\{N^{\prime}{ }_{i, t}, P^{\prime}{ }_{i, t}\right\} \quad i \neq j \text { and } Y^{\prime}{ }_{i, t} \neq X^{\prime}{ }_{i, t}
\end{gathered}
$$

The total harvest of age $\mathrm{i}$ fish is the sum of intended and unintended catches attained and defined in equation 21 .

$$
h_{i X, t}^{\text {total }}=h_{i X, t}+\tilde{h}_{i X, t}
$$

Under the imperfect fishing selectivity case, biological constraints take the form of equations 22 and 23 since the total harvest function is altered.

$$
\begin{gathered}
X_{2, t}=X_{1, t-1} s_{1}\left(1-h_{1 X, t}^{\text {total }}\right) \\
X_{3, t}=X_{2, t-1} s_{2}\left(1-h_{2 X, t}^{\text {total }}\right)
\end{gathered}
$$

The total biomass of prey and predator fish under the optimal harvesting strategy for MEY problem under a perfect selectivity case is given in figure 4 for three different trophic functions.

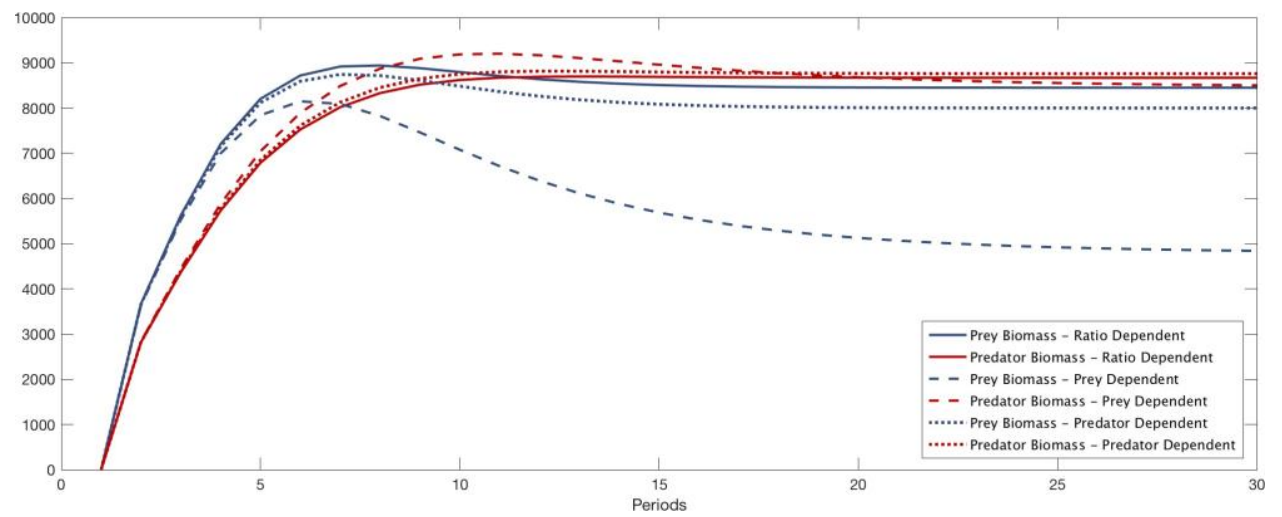

Figure 4: Biomass over Time under MEY Harvest Strategy, Perfect Fishing Selectivity

When the MEY harvesting strategy is adopted, the biomass level of both prey and predator fish increase and after the $25^{\text {th }}$ period both populations reach the steady state level, meaning that unless a shock to the environment occurs the population will remain on this level. Another finding that can be read from the figure is that, at steady state levels, prey-dependent trophic 
function gives the least favorable results in terms of biomass, whereas predator dependent and ratio dependent ones give higher levels and their results are very close to each other.

Under the imperfect fishing selectivity case, the biomass of prey and predator fish populations obtained with the optimal harvesting strategy that is the solution to MEY are given in Figure 5 .

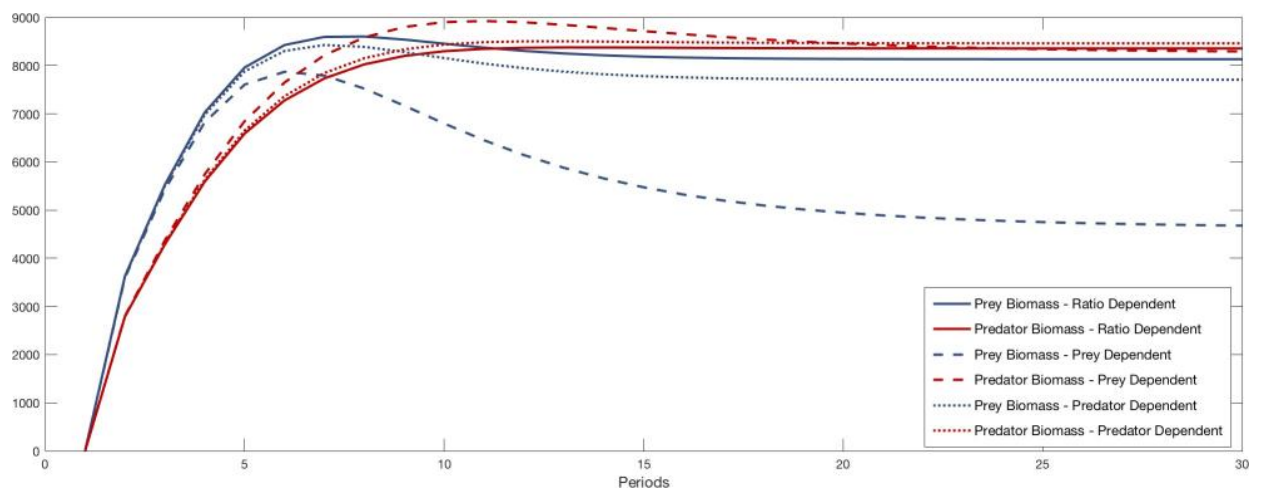

Figure 5: Biomass Over Time under MEY Harvest Strategy, Imperfect Fishing Selectivity

Similar to the perfect selectivity case, both populations increase and reach a steady state level. Also, the findings for the choice of different trophic functions give results similar to those in perfect selectivity cases.

When we compare the profit levels in perfect and imperfect selectivity cases, we see that in all three functional forms, profit levels increase. Moreover, another key finding here is the fact that imperfect fishing selectivity provides higher profits for the fishery sector compared to that of perfect fishing selectivity.

In Figure 6, rows indicate the trophic function type. Namely, the first row belongs to the prey dependent functional form, whereas the second and third rows indicate the ratio dependent and predator dependent functional forms, respectively. Also, in each row, the first column shows the perfect selectivity setup and the second column shows the imperfect selectivity setup. (e.g. second row first column - Figure 6/c - represents the harvest rate of the ratio dependent functional form under perfect fishing selectivity cases.

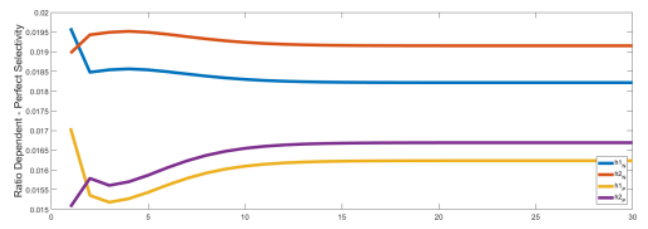

(a) Perfect Selectivity and Ratio-dependent Trophic Function

(c) Perfect Selectivity and Prey-dependent Trophic Function

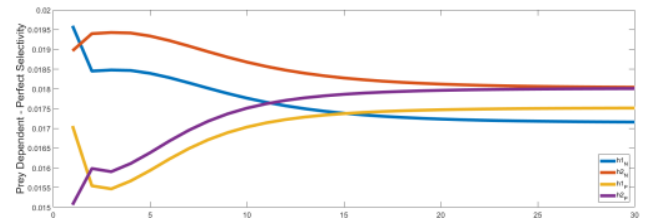

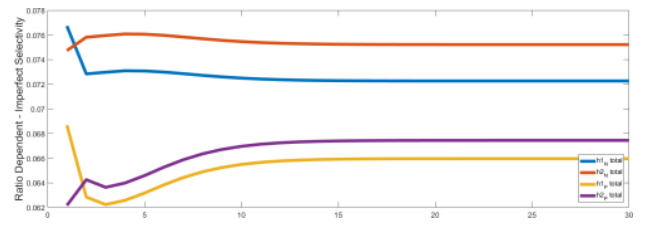

(b) Imperfect Selectivity and Ratio-dependent Trophic Function

(d) Imperfect Selectivity and Prey-dependent Trophic Function

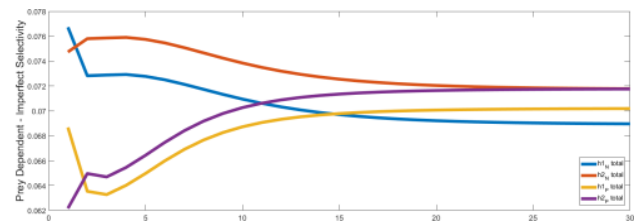


(e) Perfect Selectivity and Predator-dependent Trophic Function

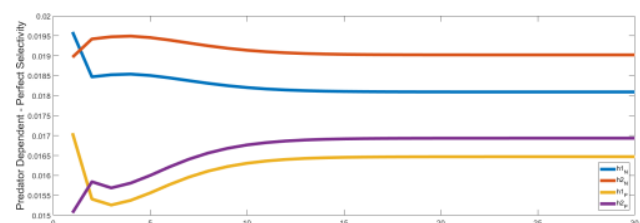

(f) Imperfect Selectivity and Predator-dependent Trophic Function

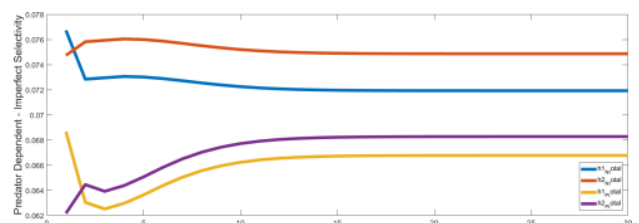

Figure 6: Solutions to the MEY Problem: Harvest Rates for Different Fishing Selectivity Cases and Trophic Functions

In each graph, the color of the lines always indicates the same cohort. The blue line indicates the young mature cohort of prey species, the red line shows the old mature cohort of prey species, whereas the yellow and purple colors show the young mature and old mature cohorts of predator species, respectively.

Another finding of the simulations is the steady state levels of harvest rates under different trophic functional forms. As can be seen from Figure 6 , at steady state levels, the preydependent trophic function has the lowest harvest rate, while the predator dependent and ratio dependent functions behave similarly and their harvest rate levels are very close to each other. Moreover, simulations of the MEY problem with imperfect fishing selectivity exhibit a higher steady state for the optimal harvesting rates than perfect fishing selectivity cases.

\section{Conclusion}

In this paper, MSY and MEY harvesting strategies for heterogeneous-species fisheries are investigated and solved numerically in an overlapping generations framework under both perfect and imperfect fishing selectivity technologies. The study repeats the analysis for three different trophic functions commonly studied in the literature in order to capture how the choice of interaction behavior between the prey and predator types alter the simulation results and thus the optimal harvesting strategies needed to achieve MSY and MEY.

In MSY optimal harvesting strategies, we find that both prey and predator populations increase and reach a steady-state level in a finite number of periods. Also, comparing the functional responses, the results for choice of different trophic functions give similar results. This implies that harvest rates are robust to the choice of trophic function under the MSY target.

In MEY optimal harvesting strategies under the perfect and imperfect selectivity cases, the proposed strategy increases biomass of both prey and predator fish populations and helps to achieve a steady-state level in a finite number of periods. Furthermore, optimal levels can be achieved with a finite level of fishing effort exerted and feasible harvest rates. The results also reveal that the choice of trophic function may not alter the main findings in the case of predator dependent and ratio dependent functions. However, the results change drastically with the preydependent function, while using the prey-dependent function results in the lowest level of total biomass at the steady state. This outcome suggests that each system should be observed and studied empirically before the simulation results are directly implemented. Another key finding is that profit levels are higher in imperfect fishing selectivity cases than perfect fishing selectivity cases. This finding actually rationalizes the usage of direct bycatch measures to implement selective fishing in command-and-control management systems since bycatch has significant adverse effects on biological sustainability. 
Fisheries management systems rely on scientific advice on MSY and MEY harvesting strategies and hence the level of total allowable catch to define fishing rights. By presenting a model analyzing the optimal harvesting strategies, this study provides a realistic setting for empirical testing for a fishery. Moreover, suggested optimal harvesting strategies can be used by policy makers to achieve the objective of sustainable fishery management by calibrating the true parameters of the respective systems and initial population levels. For real life fisheries, our main message is that not only the age-structure and fishing technologies but also preypredator interaction, should be taken into account in implementing optimal harvesting outcomes especially if the main target of the management system is to implement MEY to achieve sustainable fisheries.

The avenue for future research can include the stability analyses of the population dynamics in order to see the responses of the system to external shocks since the analytical solution is not available in characterizing MEY in our setting. For example, environmental shocks which may affect population dynamics and/or fish price shocks which may affect the target of selective fishing can be considered to better understand the long-term effects of optimal harvesting strategies on the target of achieving sustainable fisheries. 


\section{References}

Abrams, P. A., \& Ginzburg, L. R. (2000). The nature of predation: prey dependent, ratio dependent or neither? Trends in Ecology \& Evolution, 15(8), 337-341.

Ahrens, R., Allen, M., Walters, C., \& Arlinghaus, R. (2020). Saving large fish through harvest slots outperforms the classical minimum-length limit when the aim is to achieve multiple harvest and catch-related fisheries objectives. Fish and Fisheries, 1-28.

Akcakaya, H. R., Arditi, R., \& Ginzburg, L. R. (1995). Ratio dependent predation: an abstraction that works. Ecology, 76(3), 995-1004.

Arditi, R., \& Ginzburg, L. R. (1989). Coupling in predator-prey dynamics: ratio-dependence. Journal of Theoretical Biology, 139(3), 311-326.

Barnett, L. A., Branch, T. A., Ranasinghe, R. A., \& Essington, T. E. (2017). Old-growth fishes become scarce under fishing. Current Biology, 27(18), 2843-2848.

Beddington, J. R. (1975). Mutual interference between parasites or predators and its effect on searching efficiency. The Journal of Animal Ecology, 331-340.

Birkeland, C., \& Dayton, P. K. (2005). The importance in fishery management of leaving the big ones. Trends in Ecology \& Evolution, 20(7), 356-358

Botsford, L. W. (1981). Optimal fishery policy for size-specific, density-dependent population models. Journal of Mathematical Biology, 12(3), 265-293.

DeAngelis, D.L., Goldstein, R. \& O’Neill, R.V. (1975). A model for trophic interaction, Ecology 56, 881-892.

Diekert, F. K., Hjermann, D. O., Naevdal, E., \& Stenseth, N. C. (2010). Spare the young fish: optimal harvesting policies for North-East Arctic cod. Environmental and Resource Economics, 47(4), 455-475

Froese, R., Walters, C., Pauly, D., Winker, H., Weyl, O. L., Demirel, N., Tsikliras, A.C. \& Holt, S. J. (2016). A critique of the balanced harvesting approach to fishing. ICES Journal of Marine Science, 73(6), 1640-1650.

Garcia S. M., Kolding J., Rice J., Rochet M. J., Zhou S., Arimoto T., Beyer J. E.et al. (2012). Reconsidering the Consequences of Selective Fisheries. Science, 335, 1045-1047.

Getz, W. M., \& Haight, R. G. (1989). Population harvesting: demographic models of fish, forest, and animal resources (Vol. 27). Princeton University Press, Princeton, New Jersey.

Grafton, R. Q. (2012). Maximum economic yield. In A Dictionary of Climate Change and the Environment. Edward Elgar Publishing Ltd., Cheltenham, UK and Northampton, MA, USA.

Gurtin, M. E., \& Murphy, L. F. (1981). On the optimal harvesting of age-structured populations: some simple models. Mathematical Biosciences, 55(1-2), 115-136. 
Holling, C. S. (1959). Some characteristics of simple types of predation and parasitism. The Canadian Entomologist, 91 (7), 385-398.

Kanık, Z. \& Küçükşenel, S. (2016) Quota implementation of the maximum sustainable yield for age-structured fisheries, Mathematical Biosciences. 276, 59-66.

Kanık, Z. \& Küçükşenel, S. (2017) The promise of transferable fishing concessions on EU fisheries, Natural Resource Modelling, 30, e12128.

Law, R., \& Plank, M. J. (2018). Balanced harvesting could reduce fisheries-induced evolution. Fish and Fisheries, 19(6), 1078-1091.

Okuyama, T., \& Ruyle, R. L. (2011). Solutions for functional response experiments. Acta Oecologica, 37(5), 512-516.

Reed, W. J. (1980). Optimum age-specific harvesting in a nonlinear population model. Biometrics, 579-593.

Skonhoft, A., \& Gong, P. (2014). Wild salmon fishing: Harvesting the old or young?. Resource and Energy Economics, 36(2), 417-435.

Skonhoft, A., Vestergaard, N., \& Quaas, M. (2012). Optimal harvest in an age structured model with different fishing selectivity. Environmental and Resource Economics, 51(4), 525-544. 


\section{Appendix}

\section{Table 1: Parameters for MSY}

\begin{tabular}{|c|c|c|}
\hline Symbol & Definition & Value \\
\hline $\bar{a}$ & Scaling parameter in recruitment function & 1500 (number of fish) \\
\hline$\beta$ & Fertility parameter in recruitment function & 1.5 \\
\hline$b$ & Shape parameter in recruitment function & 500 (number of fish) \\
\hline$s_{0}$ & Natural survival rate of juveniles from one period to another & 0.6 \\
\hline$s_{1}$ & Natural survival rate of young matures from one period to another & 0.7 \\
\hline$s 2$ & Natural survival rate of old matures from one period to another & 0.7 \\
\hline$w_{N 0}$ & Weight of prey juveniles & 1 (kg/fish) \\
\hline$w_{N 1}$ & Weight of prey young mature & 2 (kg/fish) \\
\hline$w_{N 2}$ & Weight of prey old mature & 3 (kg/fish) \\
\hline$w_{N 3}$ & Weight of the oldest prey fish & 3 (kg/fish) \\
\hline$w_{P 0}$ & Weight of predator juveniles & 4 (kg/fish) \\
\hline$w_{P 1}$ & Weight of predator young mature & 5 (kg/fish) \\
\hline$w_{P 2}$ & Weight of predator old mature & 6 (kg/fish) \\
\hline$w_{P 3}$ & Weight of the oldest predator fish & 6 (kg/fish) \\
\hline$m_{N O}$ & Percentage of population growth originated from juvenile prey & 0.30 \\
\hline$m_{N 1}$ & Percentage of population growth originated from young mature prey & 0.33 \\
\hline$m_{N 2}$ & Percentage of population growth originated from old mature prey & 0.37 \\
\hline$m_{P 0}$ & Percentage of population growth originated from juvenile predator & 0.30 \\
\hline$m_{P 1}$ & Percentage of population growth originated from young mature predator & 0.33 \\
\hline$m_{P 2}$ & Percentage of population growth originated from old mature predator & 0.37 \\
\hline$e$ & Trophic efficiency & 0.8 \\
\hline$s$ & Encounter rate & 0.6 \\
\hline$\omega$ & Handling time & 1.75 \\
\hline$\gamma$ & Interference during foraging & 0.7 \\
\hline
\end{tabular}


Table 2: Additional Parameters for MEY

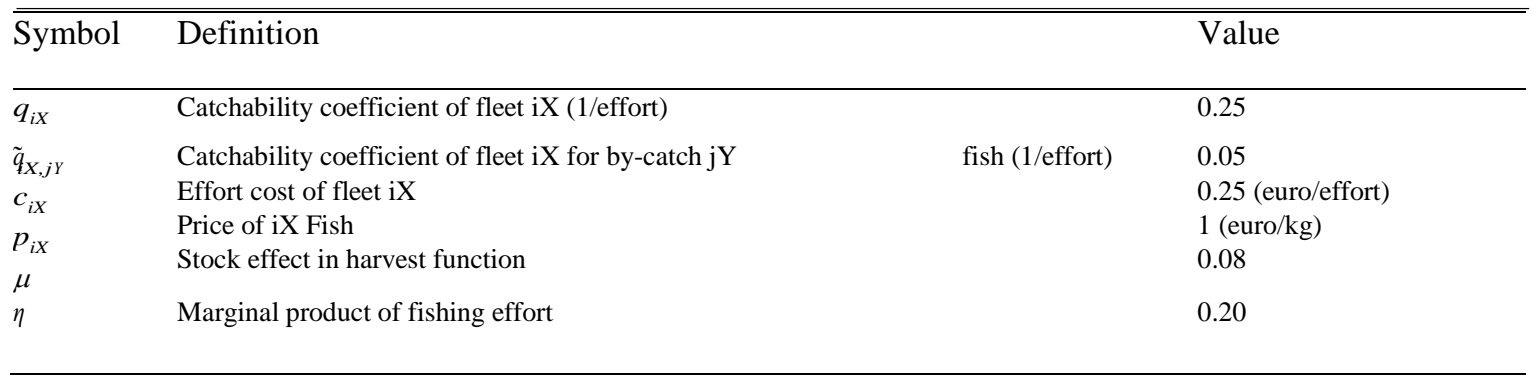

